\title{
Lipodermatosclerosis: A Commonly Misdiagnosed Complication of Chronic Venous Insufficiency
}

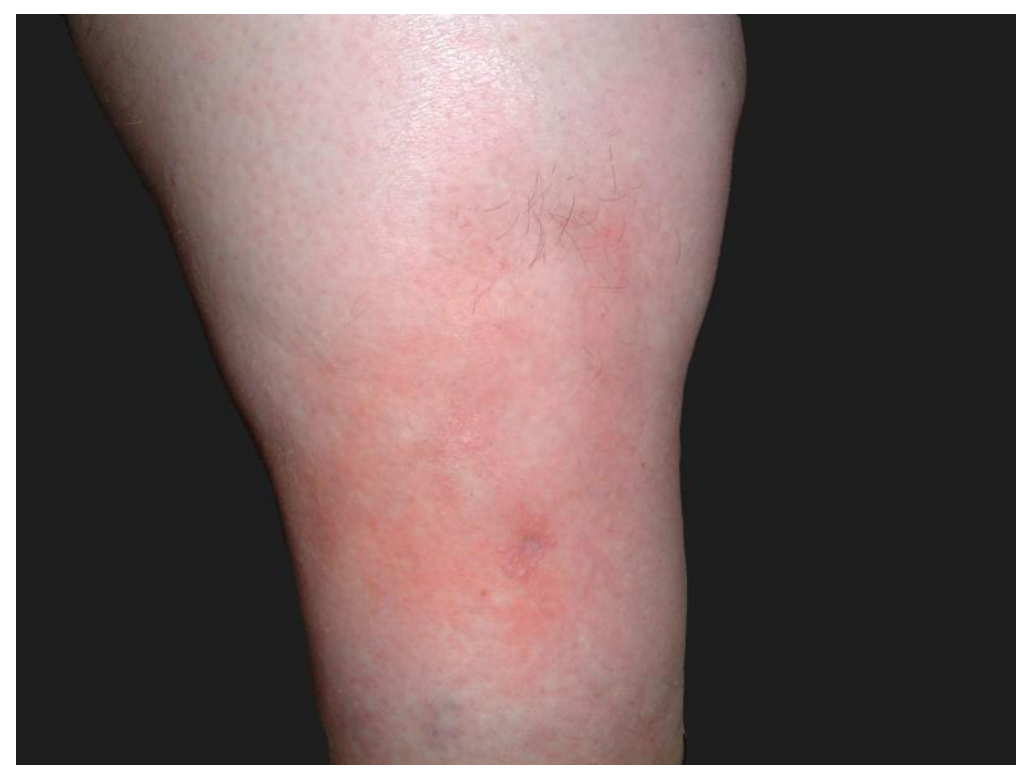

Figure. Lipodermatosclerosis on the left lower leg of a patient suffering from chronic venous insufficiency.

Mohammad Kazem Fallahzadeh, Mohammad Khalesi, and Mohammad Reza Namazi*

Medicinal and Natural Products Chemistry Research Center and Dermatology Department, Shiraz University of Medical Sciences, Shiraz, Iran

E-mail: Namazi mr@yahoo.com

Received February 11, 2010; Revised March 12, 2010; Accepted March 15, 2010; Published April 1, 2010

KEYWORDS: lipodermatosclerosis, venous insufficiency, panniculitis, fibrosis

A 50-year-old woman with a history of chronic venous disease presented with erythematous, painful, tense, bound-down plaques on the medial aspects of her lower legs, which were diagnosed as lipodermatosclerosis. 
Lipodermatosclerosis is a complication of severe chronic venous insufficiency that results from high venous pressure and resulting increased capillary permeability, perivascular fibrin cuffing, and tissue hypoxia. These events culminate in fibrosis and membranous fat necrosis[1].

Lipodermatosclerosis can present as painful, red, indurated plaques that may be easily misdiagnosed as cellulitis, thrombophlebitis, and morphea[2]. It initially develops on the medial aspect of the ankle and then spreads to involve the entire leg circumferentially[3]. In its advanced states, lipodermatosclerosis, along with a lymphedematous upper portion of the leg and an edematous foot, can look like an inverted champagne bottle[3].

Compression therapy, drugs such as stanozolol, and surgical procedures are the current therapeutic options available for this recalcitrant conundrum[2].

\section{REFERENCES}

1. Alguire, P.C. and Mathes, B.M. (2009) Pathophysiology of chronic venous disease. Uptodate 17.3 Online. Address: http://www.uptodate.com/online/content/topic.do?topicKey=vascular/5304\&selectedTitle=1 7\&source=search_result [accessed: February 10, 2010].

2. Heymann, W.R. (2009) Lipodermatosclerosis. J. Am. Aca.d Dermatol. 60, 1022-1023.

3. Alguire, P.C. and Mathes, B.M. (2009) Epidemiology and clinical manifestations of chronic venous disease. Uptodate 17.3 Online. Address: http://www.uptodate.com/online/content/topic.do?topicKey=vascular/3010\&selectedTitle=

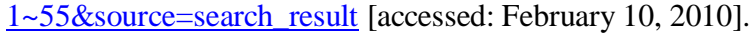

\section{This article should be cited as follows:}

Fallahzadeh, M.K., Khalesi, M., and Namazi, M.R. (2010) Lipodermatosclerosis: a commonly misdiagnosed complication of chronic venous insufficiency. TheScientificWorldJOURNAL 10, 576-577. DOI 10.1100/tsw.2010.60. 


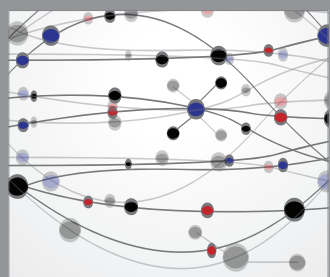

The Scientific World Journal
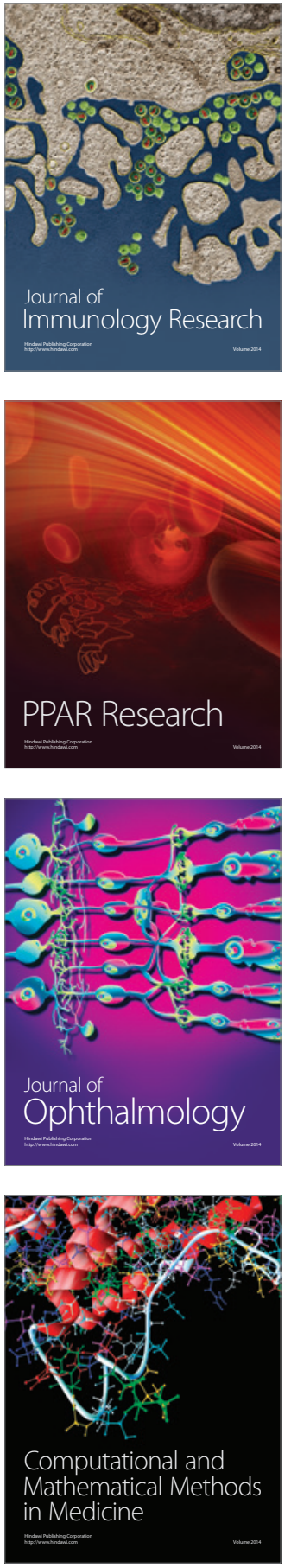

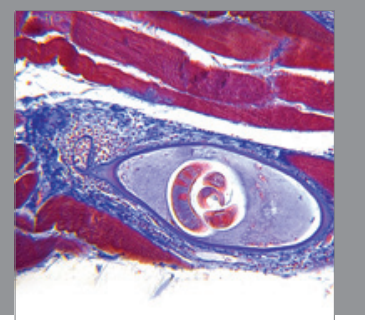

Gastroenterology

Research and Practice
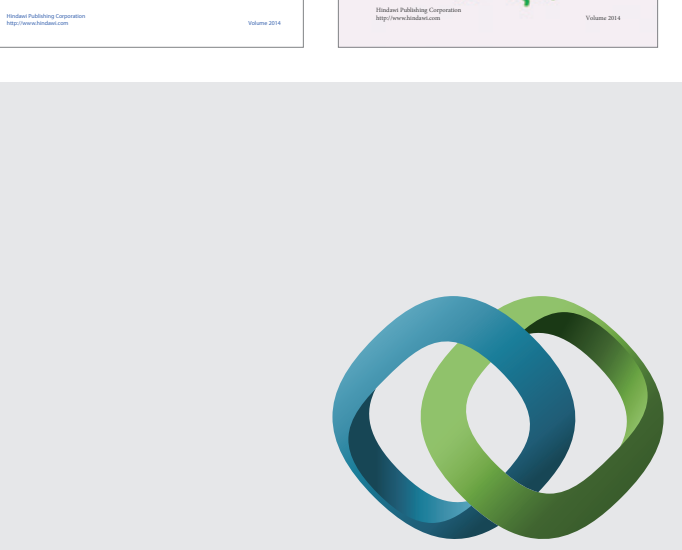

\section{Hindawi}

Submit your manuscripts at

http://www.hindawi.com
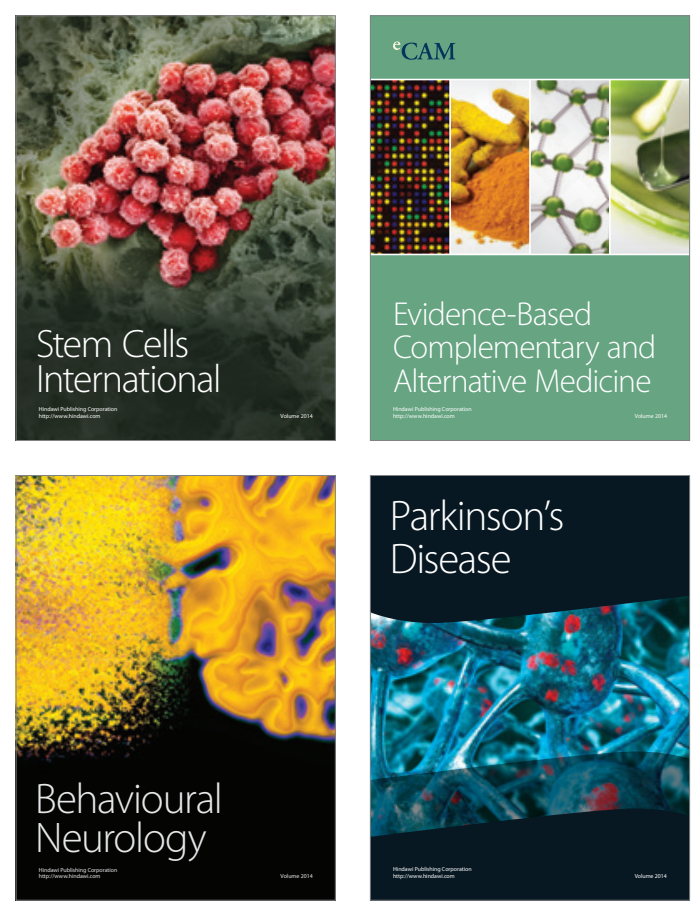

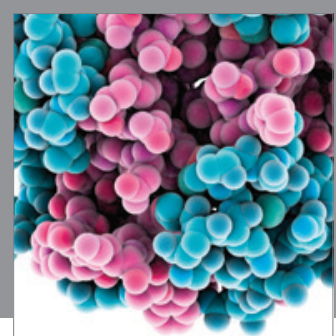

Journal of
Diabetes Research

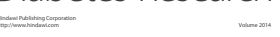

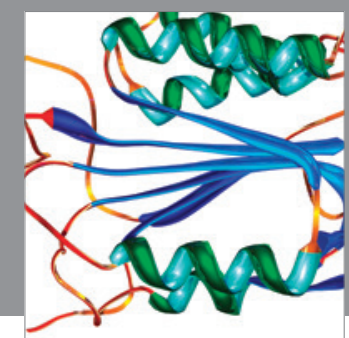

Disease Markers
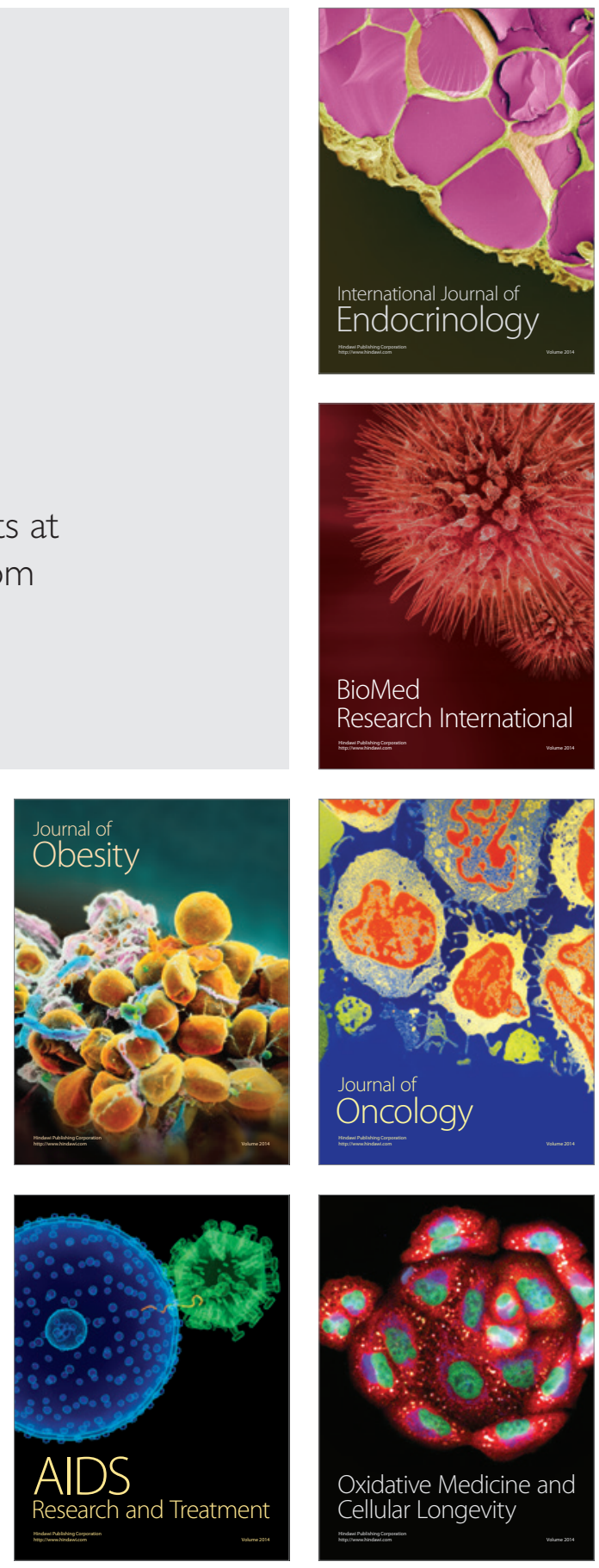